\title{
The Characteristics of Hereditary Colorectal Cancer Syndromes by Population Screening
}

\author{
Andrejs Vanags, Ilze Strumfa, Andris Gardovskis, Inga Melbarde-Gorkusa, \\ Arnis Abolins, Genadijs Trofimovics, Janis Gardovskis \\ Hereditary Cancer Institute, Riga Stradins University, Riga, Latvia
}

\begin{abstract}
Summary
Introduction. Colorectal cancer is important medical problem due to frequent occurrence and serious prognosis. Recent advances help to understand the role of heredity of colorectal carcinogenesis with possible implications for prevention.

Aim of the Study. Is to characterise hereditary colorectal cancer by population screening in order to evaluate the needs and possibilities of prevention.

Materials and methods. Population screening was performed in Valka district, evaluating the family cancer history by questionnaire. Hereditary colorectal cancer syndromes were diagnosed by internationally accepted clinical criteria.

Results. The following population frequencies were identified: hereditary non-polyposis colorectal cancer (HNPCC), $0.059 \%$ $(95 \% \mathrm{Cl}=0.033-0.106 \%)$; suspected HNPCC and familial colorectal cancer, $0.107 \%(95 \% \mathrm{Cl}=0.069-0.166 \%)$. The cancer burden among blood relatives of the affected families ranged $15.5-30.1 \%$. The mean age of colorectal cancer diagnostics was 53.7-72.0 years. The probands were mostly oncologically healthy and up to $81.8 \%$ - below 50 years of age.

Conclusions. The population frequencies of hereditary colorectal cancer syndromes correspond to significant number of cases. The high cancer burden among blood relatives of the affected families necessitates surveillance, and the age structure and health status of probands is well-suited for this.
\end{abstract}

Key words: colorectal cancer, hereditary non-polyposis colorectal cancer, population screening.

\section{INTRODUCTION}

The high incidence and mortality of colorectal cancer define this malignancy as an important medical problem (3). The role of heredity in the development of colorectal cancer is well-described $(5,6,9,10)$. Hereditary nonpolyposis colorectal cancer (HNPCC) is considered the most frequent hereditary cancer syndrome involving the large bowel (4). HNPCC is well-substantiated in the international medical literature devoted to its diagnostic criteria, molecular basis, risk evaluation and possibilities of intervention $(4,8,10)$. It has also been studied in Latvian population on hospital patient basis (5).

\section{AIM OF THE STUDY}

The aim of the present study is to characterise the hereditary colorectal cancer syndromes in Latvia by population screening approach.

\section{MATERIALS AND METHODS}

The population screening for hereditary cancer was performed in the Valka district. In collaboration with 22 family physicians, 18642 family cancer histories were collected from adult inhabitants of Valka district representing $76.6 \%$ of the population. No recruitment restrictions were applied for upper age level, gender, ethnicity or health status. Written informed consent was obtained from all patients. All patients filled in the questionnaire reporting the presence and localisation of malignant tumours in blood relatives as well as the age of patient at the time of tumour diagnosis. If the patient has died because of the tumour the death age was ascertained as well. Additional questions were asked about the treatment modalities (e.g. radiation therapy and chemotherapy, extent of operation) of affected persons in order to verify the presence of malignant tumour and to specify its location. The filled forms of family cancer history were analysed in the Hereditary Cancer Institute. HNPCC was diagnosed by Amsterdam Criteria II (4) but suspected, if at least 2 first degree relatives had HNPCC-associated cancer (colorectal, endometrial, small bowel, ureteric, renal pelvis) and at least one cancer was diagnosed before age 50. Familial colorectal cancer, variety l (FCC1) was diagnosed if colorectal cancer has been present in at least 2 first degree relatives after the age of 50. Familial colorectal cancer, variety 2 (FCC2) was diagnosed if colorectal cancer has been present in at least 2 second degree relatives at any age. The following approach to analysis was undertaken. The population frequency was calculated as the ratio between the number of diagnosed cases and the studied group. In order to characterise the course of malignant tumour, the data about the age of tumour diagnostics, age of tumour-related death and survival of the affected persons were retrieved from the questionnaires. The cancer burden was calculated as the ratio between affected persons and the whole number of blood relatives in the affected blood line. Descriptive statistical analysis using CIA software (1) was performed involving 95\% confidence interval (CI) analysis. 


\section{RESULTS}

During the population screening, 51 probands were diagnosed with hereditary colorectal cancer syndromes, including 11 cases of HNPCC syndrome (Figure 1), 20 suspected HNPCC (sHNPCC) syndrome, 15 - FCC1 and 5 - FCC2 syndrome. The corresponding population frequencies were following: HNPCC, $0.059 \%$ (95\% CI = $0.033-0.106 \%)$; sHNPCC and FCC, $0.107 \%(95 \% \mathrm{CI}=$ $0.069-0.166 \%$ ) each. No cases of familial adenomatous polyposis were revealed. The characteristics of the probands are provided in Table 1 . The age distribution (Figure 2) of probands suggests elimination of HNPCC probands with advancing age. In contrast, the chance to be diagnosed with FCC increases with age.

In order to evaluate the cancer burden and course, data about presence and location of HNPCC-related tumours were retrieved. There were 23 cases of colorectal cancer and 19 cases of endometrial cancer in HNPCC pedigrees as well as single cases of cancer in the small intestine and renal pelvis, respectively. Endometrial cancer was the dominant manifestation of the hereditary cancer syndrome in some pedigrees (Figure 3). In sHNPCC kindreds, 28 colorectal and 13 endometrial cancers were the only HNPCC-related cancers. In FCC families, 41 cases of colorectal cancer were identified. The burden of index cancers was generally high (Table 2). The mean age of cancer diagnostics and age of cancer related death is shown in the Table 3. Notably, in most groups except endometrial cancer in HNPCC, the mean age exceeds 50 years. In HNPCC, endometrial cancer is diagnosed statistically significantly earlier than colorectal cancer. The higher mean age of colorectal cancer diagnostics in FCC is related to the diagnostic criteria. The course of the malignant tumours within hereditary and familial colorectal cancer syndromes is presented in the Table 4 . The following evidence of genetic anticipation was found in HNPCC and sHNPCC kindreds. The mean age of cancer diagnostics in the oldest affected generation was 61.4 years $(95 \% \mathrm{CI}$ for the mean $(\mathrm{CIM})=56.4-66.4$ years) but in the next generation -49.8 years $(95 \%$ CIM $=44.9-54.7$ years).

In HNPCC pedigrees, $3 / 11$ (27.3\%; 95\% CI = 9.7-56.6\%) families reported presence of cancers, not included in the diagnostic criteria (i.e., colorectal, endometrial, small intestinal and renal pelvis cancer). Single cases of brain tumour $(0.7 \% ; 95 \% \mathrm{CI}=0.1-0.3 \%)$, breast cancer, lung cancer and head-and-neck cancer were reported. In 1 case, proband reported malignancy located in the abdominal cavity but not further specified. In suspected HNPCC, 22 additional cancers were present in 14/20 $(41.2 \% ; 95 \%$ CI $=26.3-57.8 \%)$ pedigrees. These included 4 cases of breast cancer $(3.0 \%$ of female blood relatives; $95 \% \mathrm{CI}=1.2-7.4 \%), 4$ cases of prostate cancer ( $3.1 \%$ of male blood relatives; $95 \% \mathrm{CI}=1.2-7.6 \%$ ), 2 cases of lung cancer $(0.8 \% ; 95 \% \mathrm{CI}=0.2-2.7 \%), 2$ cases of pancreatic cancer, 2 cases of brain tumours as well as isolated cases of head-and-neck cancer $(0.4 \% ; 95 \%$ $\mathrm{CI}=$

$0.1-2.1 \%)$, urinary bladder cancer, melanoma, Wilms tumour, gastric cancer, renal cancer, cancer of the vulva
( $0.7 \%$ of female blood relatives; $0.1-4.1 \%)$ and ovarian cancer. In FCC, 14 additional tumours were present in 10/20 (33.3\%; 95\% CI $=19.2-51.2 \%)$ families. There were 3 cases of sarcoma $(1.2 \% ; 95 \% \mathrm{CI}=0.4-3.6 \%)$, 2 cases of gastric cancer $(0.8 \% ; 95 \% \mathrm{CI}=0.2-3.0 \%), 2$ cases of prostate cancer, 2 cases of brain tumours (both in the same kindred), as well as single cases of lung cancer $(0.4 \% ; 95 \%$ CI $=0.1-2.3 \%)$, haematological malignancy, breast cancer. In 2 cases, the location of cancer was unknown to the proband.

\section{DISCUSSION}

During the Valka district population screening, both HNPCC families and pedigrees affected by other hereditary colorectal cancer syndromes were identified. The population frequencies of these syndromes were determined. In a hypothetic population of 2294590 persons that equals in size the population of Latvia in 2006 (Data bases of the Central Statistics Board, accessed 09.11.2009) but would be identical to Valka population in the age structure, gender and national composition, these frequencies would correspond to 1377 (interval, based on the 95\% CI of the relative value, 688-2295) persons diagnosed with HNPCC syndrome and 5048 (interval, based on the 95\% CI of the relative value, 3671-6654) persons diagnosed with suspected hereditary colorectal cancer syndromes. The population estimates providing the approximation of probands that might benefit from surveillance have not been described previously.

In order to estimate the magnitude of cancer risk in these pedigrees, the colorectal and endometrial cancer burden among blood relatives in the affected branch was analysed. In all syndromes, colorectal cancer burden exceeds significantly the described cumulative incidence (0-74 years) of colorectal cancer in EU that constitutes $4.53 \%$ in males and $2.70 \%$ in females (3). Although there is a trend towards higher frequency of colorectal cancer in HNPCC and FCC syndromes in comparison with sHNPCC, the difference is not statistically significant. Two important conclusions can be inferred from these data - the high frequency of colorectal cancer prompts prophylactic follow-up of persons belonging to the affected blood line. The surveillance for colorectal cancer should be equally intense for all the mentioned syndromes as the colorectal cancer frequency shows no statistically significant differences among the syndromes. The colorectal cancer burden in the evaluated families is lower than the described $80 \%$ lifetime risk in mutation carriers (8) as we had no possibility to exclude non-carriers by clinical means. However, parameter that can be evaluated on clinical basis is easy and cheap for general medical use, and can give insight in the importance of the problem.

Probands' age structure revealed that significant proportion of probands diagnosed with hereditary cancer syndromes is younger than 50 years of age. In addition, the younger age is more frequent in proband diagnosed with HNPCC and thus subjected to higher cancer risk. Thus, the age structure of probands is well-suited for 
timely initiation of surveillance. The age distribution of probands suggests elimination of HNPCC probands with advancing age. In contrast, the chance to be diagnosed with FCC increases with age as the older relatives enter the risk group. The probands mostly were oncologically healthy themselves - a finding that also suggests the possibility to reveal the persons at risk timely.

The mean age of colorectal cancer diagnostics 159.3 $(95 \%$ CI $=53.8-64.8)$ years in HNPCC, $55.2(95 \%$ $\mathrm{CI}=49.1-61.3)$ years in sHNPCC) was slightly larger than the published result of 44 years (8). However, relatively young persons at the economically active age are affected. Once the person is affected by hereditary colorectal cancer, the prognosis is serious as reflected by low survival. The death also occurs prematurely: at the mean age of $61.5(95 \% \mathrm{CI}=52.9-70.0)$ years in HNPCC, 56.7 (95\% CI = 49.9-63.5) years in suspected HNPCC and 58.7 (95\% CI $=53.6-63.8)$ years in the whole group of definitive and suspected HNPCC. Occasionally, colorectal cancer has caused death of the patients as early as 28 years of age. This early occurrence corresponds to the literature data about HNPCC (7) including even description of colorectal cancer in 19 years old patient. This also emphasizes the need to identify the persons at risk properly and to provide adequate follow-up possibilities. Onset of hereditary colorectal cancer after the age of 50 is also well-known phenomenon that is described even in known mutation carriers (7). Thus, surveillance measures in risk persons should not be cancelled at this age as both the obtained data and literature publications suggest permanent cancer risk.

The age of colorectal cancer diagnostics in FCC families was higher (mean, 72.0 years; 95\% CI $=67.3-76.7$ years) as predicted by the diagnostic criteria. However, the frequency of colorectal cancer among blood relatives in these pedigrees was not lower.

The frequency of endometrial cancer among females was significant: $22.4 \%(95 \% \mathrm{CI}=14.8-32.3 \%)$ among female blood relatives in HNPCC families and 9.6\% $(95 \%$ CI $=5.7-15.8 \%)$ in sHNPCC families. It exceeds the cumulative incidence $(0-74$ years $)$ in the EU estimated as $1.5 \%$ (3). There is a trend towards lower endometrial cancer risk in sHNPCC families. Although the difference is not statistically significant, further studies in larger group would be necessary to gain more information in larger group.

The endometrial cancer was diagnosed at the mean age $48.4(95 \% \mathrm{CI}=43.4-53.4)$ years in HNPCC families, $50.5(95 \% \mathrm{CI}=43.0-58.0)$ years in the sHNPCC families and $49.4(95 \% \mathrm{CI}=45.1-53.7)$ years in the whole group of definitive and suspected HNPCC. The youngest case was diagnosed with the endometrial cancer at the age of 27 years. Thus, again, females were affected by endometrial cancer at the economically active age. The affected women mostly were alive at the time when population screening was carried out: 17/19 (89.5\%; $95 \%$ CI $=68.6-97.1 \%)$ in HNPCC, $7 / 13$ (53.8\%; 95\% $\mathrm{CI}=29.1-76.8 \%)$ in suspected HNPCC and 24/32 (75\%; $95 \% \mathrm{CI}=57.9-86.7 \%)$ in the whole group of definitive and suspected HNPCC. The proportion of living persons in the groups of colorectal and endometrial cancer groups was significantly different. Thus, the prognosis is probably better than in case of colorectal cancer; however, the high frequency suggests the need for surveillance. The beneficial prognosis of endometrial cancer in the setting of HNPCC is in agreement with the published data $(2,12)$.

Although cancers in locations other than colorectal, endometrial, small intestinal and renal pelvis were noted, the frequency was low and no dominant location was observed. Among unusual findings, 2 cases of childhood CNS tumours in a single FCC pedigree and several sarcomas in different FCC families were recorded.

We have shown previously (11) that the population screening has shown higher yield of definitive hereditary colorectal cancer syndrome diagnostics than evaluation of hospital patients treated for cancer (the approach further designated in short as hospital screening). The yield of suspected hereditary colorectal cancer syndromes by population screening also has been high in this comparative aspect. The frequency of definitive hereditary colorectal cancer in Latvia by hospital screening data is less than reported from Sweden, Denmark, Finland, Italy, USA and Israel, where the incidence of definitive hereditary colorectal cancer by Amsterdam criteria is $0.5-1.5 \%$ of all newly diagnosed colorectal cancer cases, and significantly less than the frequency $3.2 \%$ of hereditary colorectal cancers among all colorectal cancers in German population but is close to the frequency of $0.3 \%$ in the United Kingdom (5). Thus, hospital screening yields lower number of definitive colorectal cancer than in other Western type societies. Hypothetically, lower frequency of definitive hereditary colorectal cancer in any particular country can be explained by ethnic differences as well as by frequency of factors causing sporadic colorectal cancer. Alternatively, it may be hypothesised that the trend towards higher frequency of hereditary colorectal cancer as revealed by population screening is more in line with other European data and thus can be considered true.

\section{CONCLUSIONS}

1. Blood relatives of the HNPCC, sHNPCC and FCC pedigrees are subjected to increased cancer risk that can be approximated by the clinical evaluation of cancer family history at low cost.

2. The course of cancer is unfavourable; considering the two frequent locations, colorectal cancer has worse prognosis than endometrial cancer. In order to prevent cancer development and to prevent the economic loss caused by death or by durable disability of economically active persons, surveillance should be offered in order to start active treatment at precancerous conditions or the cancer at early stage.

3. The age structure and health status of probands is well-suited for surveillance and/or prophylaxis.

4. Population screening discloses more patients at risk 
and also brings more information about the real burden of hereditary colorectal cancer in Latvia despite the fact that population screening faces the same problems as the hospital screening in Latvia incomplete medical information about malignant tumours in previous generations due to several historical reasons.

\section{Conflict of interest: None}

\section{REFERENCES}

1. Altman D, Machin D, Bryant T, Gardner S. Statistics with confidence: confidence interval and statistical guidelines // 2nd edition, Bristol: BMJ Books, 2000.

2. Boks DE, Trujillo AP, Voogd AC, Morreau H, Kenter GG, Vasen HF. Survival analysis of endometrial carcinoma associated with hereditary nonpolyposis colorectal cancer // Int J Cancer, 2002; 102: $198-200$

3. Boyle P and Ferlay J. Cancer incidence and mortality in Europe, 2004 // Ann Oncol, 2005; 16: 481 - 488

4. Guillem JG, Wood WC, Moley JF, Berchuck A, Karlan BY, Mutch DG, Gagel RF, Weitzel J, Morrow M, Weber BL, Giardiello F, Rodriguez-Bigas MA, Church J, Gruber S, Offit K. ASCO/SSO review of current role of risk-reducing surgery in common hereditary cancer syndromes // Ann Surg Oncol, 2006; 13:1296-1321

5. Irmejs A, Borosenko V, Melbarde-Gorkusa I, Gardovskis A, Bitina M, Kurzawski G, Suchy J, Gorski B, Gardovskis J. Nationwide study of clinical and molecular features of hereditary non-polyposis colorectal cancer (HNPCC) in Latvia // Anticancer Res, 2007; 27: $653-658$

6. Lynch HT, de la Chapelle A. Hereditary colorectal cancer // NEJM, 2003; 348(10):919 - 932

7. Lynch HT, Riley BR, Weissman S, Coronel SM, Kinarsky Y, Lynch JF, Shaw TG, Rubinstein WS. Hereditary nonpolyposis colorectal carcinoma (HNPCC) and HNPCC-like families: problems in diagnosis, surveillance and management // Cancer, 2004; 100(1):53- 64

8. Lynch HT, Shaw MW, Magnuson CW, Larsen AL, Krush AJ. Hereditary factors in two large midwestern kindreds // Arch Intern Med, 1996; 117:206 - 212

9. Lynch HT, Smyrk TC, Watson P, Lanspa SJ, Lynch JF, Lynch PM, Cavalieri RJ, Boland CR. Genetics, natural history, tumor spectrum, and pathology of hereditary non-polyposis colorectal cancer: an updated review // Gastroenterology, 1993; 104:1535 - 1549

10. Trimbath JD, Giardiello FM. Review article: genetic testing and counselling for hereditary colorectal cancer // Aliment Pharmacol Ther, 2002; 16: $1843-1857$
11. Vanags A, Irmejs A, Borosenko V, Gardovskis A, Miklasevics E, Gardovskis J. Comparison of the expedience of population and hospital screening in hereditary cancer detection // Collection of Scientific papers 2008, Riga Stradiņš University, 2009; $31-37$

12. Vasen HF, Watson P, Mecklin JP, Jass JR, Green JS, Nomizu T, Müller H, Lynch HT. The epidemiology of endometrial cancer in hereditary nonpolyposis colorectal cancer // Anticancer Res, 1994; 14: $1675-1678$

\section{ACKNOWLEDGEMENTS}

The population screening was carried out within the frames of the project "The development of hereditary cancer prophylaxis in Estonia and Latvia" co-financed by European Union Interreg IIIB Neighbourhood program and including participation of the following Valka district family physicians: Maruta Bindre, Lilita Ezerina, Juris Ezerins, Elvira Freiberga, Alla Grinberga, Sanita Jansone, Alda Karklina, Maija Klavina, Ritma Klavina, Marianna Kire, Valdis Kiris, Zane Lukina, Inga Natra, Maris Natra, Liga Putrina, Olga Ribkina, Anna Sakare, Ilona Uzbeka, Inese Verselo, Sniedze Viksna, Maija Zalite, Liga Ziemele. AV is supported by ESF fellowship, project Nr. 2009/0147/1DP/1.1.2.1.2/09/ IPIA/VIAA/00
Address:
Andrejs Vanags,
Hereditary Cancer Institute,
Riga Stradins University,
Dzirciema Street 16, LV-1007,
Riga, Latvia,
E-mail: vanags314@inbox.lv 
Table 1. Characteristics of the probands diagnosed with hereditary or familial colorectal cancer syndromes

\begin{tabular}{|c|c|c|c|c|c|}
\hline Syndrome & $\begin{array}{c}\text { < 50 years: } \\
\text { F, [95\% CI] }\end{array}$ & $\begin{array}{c}\text { Females: } \\
\text { F, \% [95\% CI] }\end{array}$ & $\begin{array}{c}\text { Males: } \\
\text { F, \% [95\% CI] }\end{array}$ & $\begin{array}{c}\text { Oncologically } \\
\text { healthy: } \\
\text { F, } \% \text { [95\% CI] }\end{array}$ & $\begin{array}{c}\text { Cancer } \\
\text { location }\end{array}$ \\
\hline HNPCC & $81.8[52.3-94.9]$ & $70.0[39.7-89.2]$ & $30.0[10.8-60.3]$ & $81.8[52.3-94.9]$ & 2 CRC \\
\hline sHNPCC & $45.0[25.8-65.8]$ & $90.0[69.9-97.2]$ & $10.0[2.8-30.1]$ & $90.0[69.9-97.2]$ & CRC, Br \\
\hline FCC & $27.8[12.5-50.9]$ & $89.5[68.6-97.1]$ & $10.5[2.9-31.4]$ & $95.0[76.4-99.1]$ & CRC \\
\hline
\end{tabular}

Abbreviations in the Table: F, frequency; CI, confidence interval; HNPCC, hereditary non-polyposis colorectal cancer; sHNPCC, suspected hereditary non-polyposis colorectal cancer; FCC, familial colorectal cancer; CRC, colorectal cancer; Br, breast cancer

Table 2. Comparison of different hereditary and familial colorectal cancer syndromes by frequency of index cancers in blood relatives of the affected pedigrees

\begin{tabular}{|c|c|c|c|}
\hline \multirow{3}{*}{ Syndrome } & Tumour location & Frequency, \% & $95 \%$ CI, \% \\
\hline \multirow{3}{*}{ HNPCC } & Index cancers & 30.1 & $23.3-38.0$ \\
\cline { 2 - 4 } & Colorectal cancer & 15.8 & $10.7-22.5$ \\
\cline { 2 - 4 } & Endometrial cancer & $14.8-32.3^{1}$ \\
\hline \multirow{2}{*}{ sHNPCC } & Index cancers & $22.4^{1}$ & $11.6-20.3$ \\
\cline { 2 - 4 } & Colorectal cancer & 15.5 & $7.4-14.8$ \\
\cline { 2 - 4 } & Endometrial cancer & 10.6 & $5.7-15.8^{1}$ \\
\hline FCC & Colorectal cancer & 9.6 & $12.8-22.3$ \\
\hline
\end{tabular}

${ }^{1}$ in female

Abbreviations in the Table: CI, confidence interval; HNPCC, hereditary non-polyposis colorectal cancer; sHNPCC, suspected hereditary non-polyposis colorectal cancer; FCC, familial colorectal cancer

Table 3. Comparison of hereditary and familial colorectal cancer syndromes by age of tumour manifestation

\begin{tabular}{|c|c|c|c|c|}
\hline \multirow[t]{2}{*}{ Syndrome } & \multicolumn{2}{|c|}{ Age of diagnosis } & \multicolumn{2}{|c|}{ Age of death } \\
\hline & Interval & Mean (95\% CIM) & Interval & Mean (95\% CIM) \\
\hline HNPCC & $30-77$ & $54.2(50.2-58.2)$ & $28-89$ & $61.7(54.2-69.2)$ \\
\hline CRC & $36-77$ & $59.3(53.8-64.8)$ & $28-89$ & $61.5(52.9-70.0)$ \\
\hline $\mathrm{Ut}$ & $30-65$ & $48.4(43.4-53.4)$ & $37-72$ & NA \\
\hline sHNPCC & $27-82$ & $53.7(49.1-58.3)$ & $28-88$ & $55.5(49.5-61.5)$ \\
\hline $\mathrm{CRC}$ & $28-82$ & $55.2(49.1-61.3)$ & $32-88$ & $56.7(49.9-63.5)$ \\
\hline Ut & $27-72$ & $50.5(43.0-58.0)$ & $28-73$ & $51.2(33.1-69.3)$ \\
\hline FCC & $41-89$ & $72.0(67.3-76.7)$ & $52-90$ & $76.3(73.1-79.5)$ \\
\hline
\end{tabular}

Abbreviations in the Table: CIM, confidence interval for the mean; HNPCC, hereditary non-polyposis colorectal cancer; CRC, colorectal cancer; Ut, endometrial cancer; sHNPCC, suspected hereditary non-polyposis colorectal cancer; FCC, familial colorectal cancer

Table 4. The course of the malignant tumours within hereditary and familial colorectal cancer syndromes

\begin{tabular}{|c|c|c|c|c|c|}
\hline \multirow[t]{2}{*}{ Syndrome } & \multicolumn{2}{|c|}{ First-year lethality } & \multirow{2}{*}{$\begin{array}{c}\text { Survival, years }(95 \% \\
\text { CI })\end{array}$} & \multicolumn{2}{|r|}{ Alive } \\
\hline & $\mathrm{N}$ & F, \% $(95 \% \mathrm{CI})$ & & $\mathrm{N}$ & F, \% $(95 \% \mathrm{CI})$ \\
\hline HNPCC & $8 / 44$ & $18.2(9.5-32.0)$ & $2.6(0-5.2)$ & $23 / 44$ & $52.3(37.9-66.2)$ \\
\hline $\mathrm{CRC}$ & $6 / 23$ & $26.1(12.5-46.5)$ & $1.7(0.6-2.7)$ & $6 / 23$ & $26.1(12.5-46.5)$ \\
\hline $\mathrm{Ut}$ & $1 / 19$ & $5.3(0.9-24.6)$ & 8.5 & $17 / 19$ & $89.5(68.6-97.1)$ \\
\hline sHNPCC & $14 / 42$ & $25.0(15.5-37.7)$ & $2.3(1.1-3.5)$ & $14 / 42$ & $33.3(21.0-48.4)$ \\
\hline CRC & $10 / 29$ & $34.5(19.9-52.6)$ & $2.5(1.2-3.8)$ & $7 / 29$ & $24.1(12.2-42.1)$ \\
\hline Ut & $4 / 13$ & $30.8(12.7-57.6)$ & $1.5(0-3.5)$ & $7 / 13$ & $53.8(29.1-76.8)$ \\
\hline FCC & $10 / 41$ & $24.4(13.8-39.3)$ & $2.2(1.3-3.1)$ & $5 / 41$ & $12.2(5.3-25.5)$ \\
\hline
\end{tabular}

Abbreviations in the Table: N, absolute number; F, frequency; CI, confidence interval; HNPCC, hereditary nonpolyposis colorectal cancer; CRC, colorectal cancer; Ut, endometrial cancer; sHNPCC, suspected hereditary nonpolyposis colorectal cancer; FCC, familial colorectal cancer 


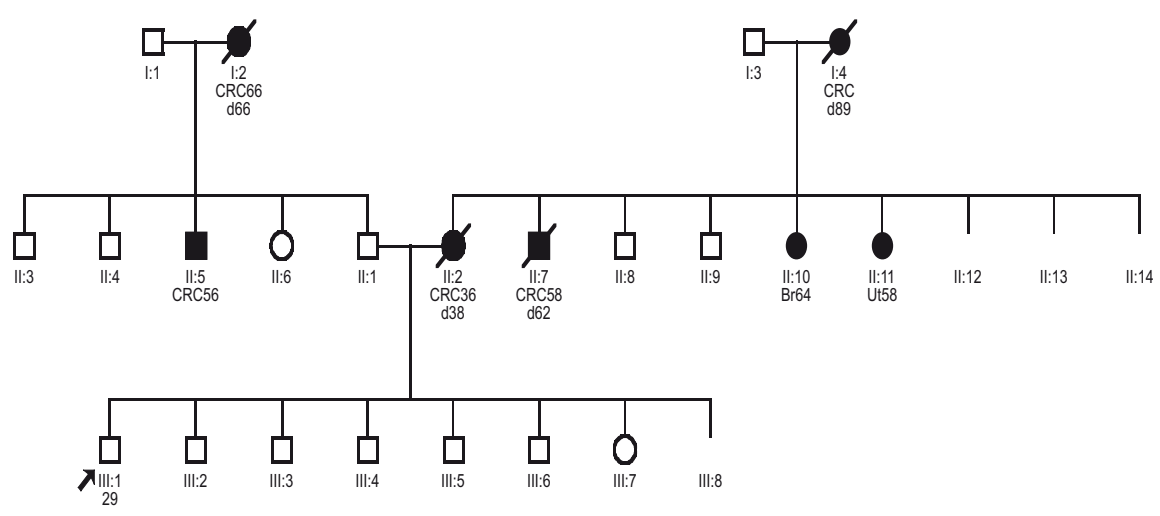

Fig. 1. Pedigree corresponding to the diagnostic criteria of hereditary non-polyposis colorectal cancer syndrome. The pedigree shows also 2 late-onset cases of colorectal cancer in the paternal line that should be considered separately. Abbreviations in the Figure: CRC, colorectal cancer; Br, breast cancer; Ut, endometrial cancer; $d$, dead. The age of cancer diagnostics is shown by number following the diagnosis, and the age of death is shown by the number, following the abbreviation " $d$ ". The proband is indicated by an arrow

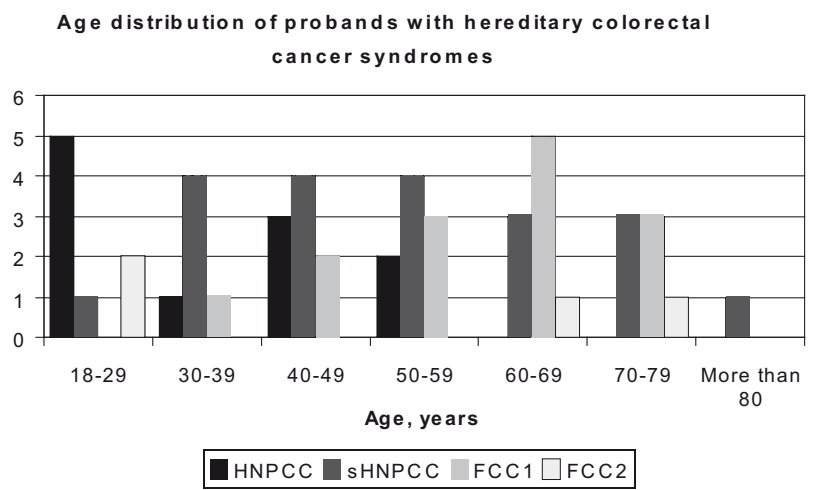

Fig. 2. Age distribution of probands diagnosed with hereditary colorectal cancer syndromes. Abbreviations in the Figure: HNPCC, hereditary non-polyposis colorectal cancer; sHNPCC, suspected hereditary nonpolyposis colorectal cancer; FCC1, familial colorectal cancer, variety 1; FCC2, familial colorectal cancer, variety 2

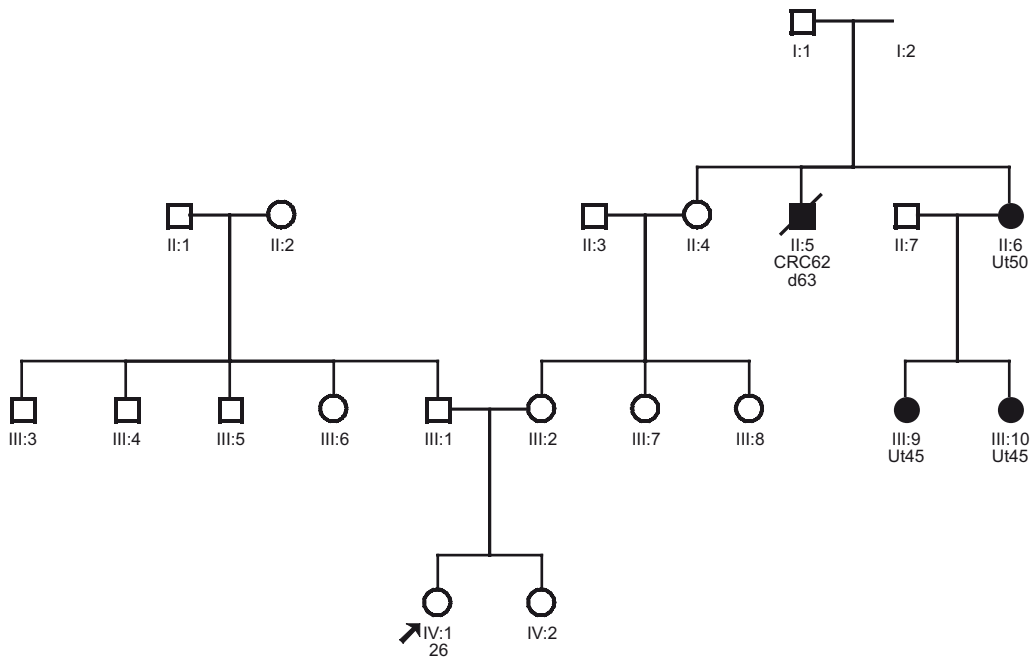

Fig. 3. Hereditary non-polyposis colorectal cancer kindred with predominance of endometrial cancer. Abbreviations in the Figure: CRC, colorectal cancer; Ut, endometrial cancer; $d$, dead. The age of cancer diagnostics is shown by number following the diagnosis, and the age of death is shown by the number, following the abbreviation " $d$ ". The proband is indicated by an arrow 